\title{
Effects of density and size distribution on the erosion of the adult cockle Cerastoderma edule
}

\author{
JOSE ANTA, ENRIQUE PEÑA and JERÓNIMO PUERTAS \\ ${ }^{1}$ Environmental and Water Engineering Group, University of A Coruña, Campus de Elviña s/n, 15071 A Coruña, Spain. \\ E-mail: jose.anta@udc.es
}

SUMMARY: A series of experimental flume experiments were carried out to evaluate the passive transport of the adult cockle Cerastoderma edule with shell sizes from 15 to $35 \mathrm{~mm}$. The purpose of the study was to measure the erosion of this bivalve under controlled laboratory conditions, reproducing the current velocities and the cockle size distribution found at the Lombos do Ulla river mouth in Spain during high river discharges. Increasing velocities $(0.29,0.31,0.35,0.40,0.44$ and 0.47 $\mathrm{m} \mathrm{s}^{-1}$ ) were applied to the bivalves, analysing the influence of population density (500 and 1000 ind. $\mathrm{m}^{-2}$ ), activity (live vs dead individuals), and mollusc size and distribution. To assess the effect of bivalve size distribution on the cockle transport, uniform and non-uniform cockle size distributions were tested. The particle image velocimetry technique and the doubleaveraged methodology were used to determine velocity fields during the experiments. In the experiments cockle erosion rates were found to be directly related to the flow velocity and inversely related to the population density. The erosion behaviour of uniform and graded cockle size distributions showed differences similar to those found in the bedload transport of uniform and non-uniform sediment mixtures. Our results provide a mechanism to explain the observed physical transport of bivalve populations after large storm events.

Keywords: Cerastoderma edule, erosion, flume experiments, particle image velocimetry, double-averaged methodology.

RESUMEN: EFECTO DE LA DENSIDAD DE POBLACIÓN Y LA DISTRIBUCIÓN DE TALLAS EN LA EROSIÓN DE BERBERECHOS CERASTODERMA EDULE ADULTOS. - En este trabajo se han desarrollado una serie de ensayos en laboratorio analizando el transporte de berberechos Cerastoderma edule adultos de tamaños de entre 15 y $35 \mathrm{~mm}$. El objetivo del estudio ha sido medir la erosión de este bivalvo bajo condiciones controladas de laboratorio, reproduciendo las velocidades y la distribución de tamaños del berberecho del banco marisquero de Os Lombos do Ulla (España) durante episodios de caudales altos en la desembocadura del río. Una serie de velocidades crecientes $\left(0.29,0.31,0.35,0.40,0.44\right.$ y $\left.0.47 \mathrm{~m} \mathrm{~s}^{-1}\right)$ fueron aplicadas a los bivalvos, analizando la influencia de la densidad de población ( $500 \mathrm{y} 1000$ ind. $\mathrm{m}^{-2}$ ), la actividad (berberechos vivos vs muertos), y la talla y distribución de tamaños. Para estudiar el efecto de la distribución de tamaños de los bivalvos en su transporte se emplearon distribuciones uniformes y no uniformes de berberechos. Para estimar los campos de velocidades durante los experimentos se aplicó la técnica de velocimetría láser de partículas (PIV) y la metodología del doble promediado (DA). En los experimentos se halló que el transporte de los berberechos está directamente relacionado con la velocidad del flujo e inversamente relacionado con la densidad de población. Los procesos de erosión de las distribuciones de berberechos uniformes y graduadas presentaron diferencias similares a las halladas en el transporte de mezclas de sedimentos uniformes y no uniformes. Los resultados obtenidos proporcionan un mecanismo que explica el transporte observado de las poblaciones de bivalvos después de grandes episodios de tormenta.

Palabras clave: Cerastoderma edule, erosión, ensayos en laboratorio, Velocimetría de Imagen de Partículas (PIV), Metodología del Doble Promediado (DA).

\section{INTRODUCTION}

Many marine bivalves continue to disperse after settlement and metamorphosis (e.g. Commito et al. 1995, Hunt et al. 2007). The post-settlement disper- sal of juvenile and adult individuals in soft-bottom habitats can be influenced by both behavioural (active) processes and physical factors which may induce passive transport, such as bedload or suspended load. Some marine invertebrates may favour their dispersal 
during their first juvenile stages by generating byssus threads (Sidgursson et al. 1976). This type of active post-settlement dispersal has been found in Cerastoderma edule juveniles in both laboratory experiments (de Montaudouin 1997, de Montaudouin et al. 2003) and field studies (de Montaudouin and Bachelet 1996).

In intertidal and subtidal sandflats, the sediment transport caused by currents and wave action interacts with the population structure of juvenile and adult surface dwelling organisms. Several field studies have shown that sediment bedload along the bottom, as well as waves and wind action, are often related to the proportion of mobilized individuals (e.g. Commito et al. 1995, Hunt et al. 2007). Flume experiments have shown that erosion of post-settled benthic organisms usually increases with flow velocity and depends on grain size distribution and the organism's type, size and activity (Roegner et al. 1995, Hunt 2004, Lundquist et al. 2004, Jennings and Hunt 2009). However, most of the laboratory experiments have been conducted with larvae and juvenile individuals but only a few have dealt with large $(>15 \mathrm{~mm})$ bivalve dispersal (St-Onge and Miron 2007, Peña et al. 2008, Redjah et al. 2010)

In intertidal environments waves and currents dominate the bottom shear stress generation while for subtidal systems tidal and wind-induced currents are often the main forcing mechanism causing bedload transport and the associated invertebrate dispersal. However, rates of dispersal do not have a linear or monotonic relationship with bottom shear stress because of the interaction of sediment erodibility and species behavioural responses (Ciutat et al. 2007). This is especially true for some infaunal organisms, for which an ability to burrow or emerge from the substrate would modify their erosion capacity (e.g. Lundquist et al. 2004, Valanko et al. 2010).

Due to the small size of the siphons, the cockle Cerastoderma edule lives near the surface (at a depth of $0-5 \mathrm{~cm}$ ) and is therefore more exposed to hydrodynamic forcing than other organisms which live deeply within the sediment. Richardson et al. (1993) analysed the effect of population density in the emergence patterns of the Cerastoderma edule. The authors analyse the activity of four aggregated bivalve clumps with different densities $\left(58,130,260\right.$ and 535 ind. $\mathrm{m}^{-2}$ ). For highdensity patches, collisions between individuals cause the cockles to emerge, making them more susceptible to being rolled by currents. The authors also performed experiments of illumination and darkness cycles showing that the cockles show immediate emergence patterns after a sudden onset of darkness. This pattern will therefore occur naturally, responding to covering by sediment during sporadic storm-induced burial.

In this study, we conducted a series of flume experiments emulating stormy hydrodynamic conditions on the commercial shellfish bed Lombos do Ulla at the mouth of the River Ulla. In this area, several mortality episodes of the cockle Cerastoderma edule and the clams Ruditapes decussatus and Venerupis senegalien- sis have been recorded. Most of these massive mortalities are caused by sudden drops in salinity. However, after some flooding events, a relocation of the bivalve stocks from the shallow to the deeper shellfish bed area was observed (Parada et al. 2007). Our study aims to analyse the specific dispersal process linked to these high flows. For this purpose, we set the experimental flow velocities, cockle densities and size distributions as the values found at the study area. The experimental tests were conducted in a racetrack flume and the velocity fields were determined using the particle image velocimetry (PIV) flow visualization technique. This non-intrusive laser technology has allowed us to obtain unsteady 2D velocity fields over the cockle patches. An integrated flume experiment of these factors for large bivalves has not yet been thoroughly and systematically investigated, and would provide a better understanding of the transport processes and their influence on the distribution of these benthic communities after storm events.

\section{MATERIALS AND METHODS}

\section{Study area}

The study site is located at the estuary of the River Ulla (Fig. 1). The Lombos do Ulla (Ulla's dunes) commercial shellfish bed is located at the river mouth and is one most of the important cockle and clam shellfish beds in Galicia (Spain). This natural sandy formation, with a total area of 1134.7 ha, is characterized by dune bedforms covering almost the entire surface of the shellfish bed $(-91 \%)$, with a mean depth ranging from -1 to $+1 \mathrm{~m}$ relative to mean tide level. The shellfish bed also has a muddy bed formation at the north of Cortegada Island with depths ranging from 2 to $4 \mathrm{~m}$ below mean sea level (Parada et al. 2006).

Tidal currents, caused by a tidal cycle with an amplitude of $3.6 \mathrm{~m}$, and the fluvial flow regime are responsible for the hydrodynamics of the river mouth where the shellfish bed is located. The River Ulla's mean discharge is about $30 \mathrm{~m}^{3} \mathrm{~s}^{-1}$, while in storm conditions it may easily rise to $120 \mathrm{~m}^{3} \mathrm{~s}^{-1}$ or more. Numerical simulations of the river mouth reveal that in the mean tide regime, the current velocities range from $\sim 0.3 \mathrm{~m}$ $\mathrm{s}^{-1}$ to $\sim 0.15 \mathrm{~m} \mathrm{~s}^{-1}$ for the sandy and muddy regions, respectively during the ebb tides and a river discharge of $30 \mathrm{~m}^{3} \mathrm{~s}^{-1}$. With combined high flows and spring tides, the maximum current velocity reaches $\sim 0.5$ to $0.6 \mathrm{~m} \mathrm{~s}^{-1}$ for the shallow area while in the deeper shellfish zone it remains almost constant (Cea et al. 2010).

\section{Cockle characterization}

The cockle found at the studied river mouth is Cerastoderma edule. The cockle's size distribution and the density of the stocks are estimated annually as part of the recovery plan of the shellfish bed developed by the Galician Regional Government (Parada et al. 

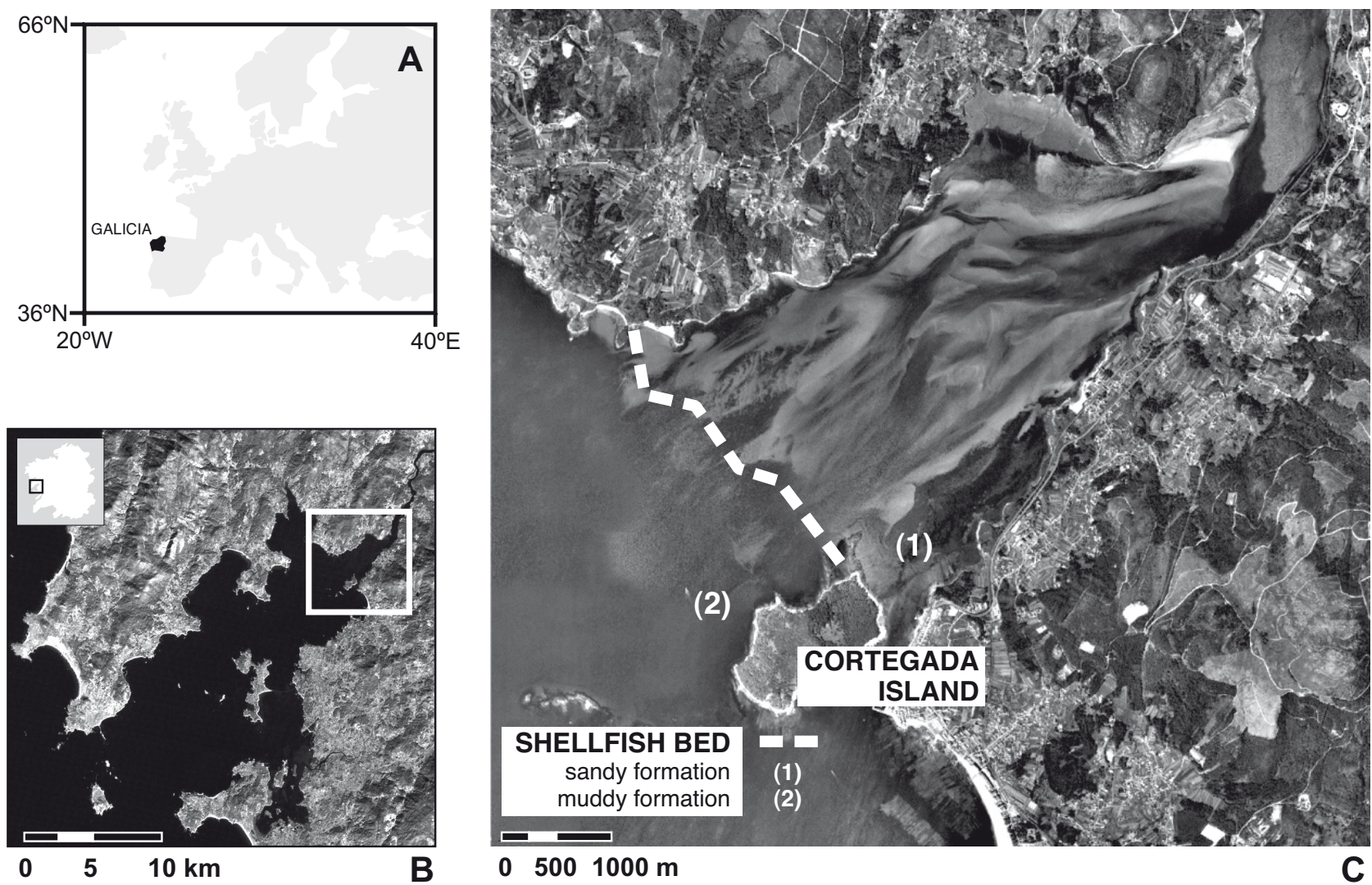

$05001000 \mathrm{~m}$

Fig. 1. - Location of the study site at the Ulla estuary (A, B) and the Lombos do Ulla shellfish bed at the river mouth (C). After severe storms, the cockle stocks have been relocated from the sandy (1) to the muddy (2) region of the shellfish bed.

2006). The sampling data are collected at the beginning and end of the harvest season at the shellfish bed in September and April, respectively. The cockle's size distribution and density show annual spatial and temporal fluctuations. From 2002 to 2006, the average recorded cockle size was 16.8 and $21.5 \mathrm{~mm}$ in September and April, respectively (Parada et al. 2006). During this period, the average density of the bivalves on the bank was about 400 to 500 ind. $\mathrm{m}^{-2}$, but some patches showed higher densities of 1000 to 2000 ind. $\mathrm{m}^{-2}$ (Molares et al. 2007).

In the flume tests, samples of this mollusc were extracted from the shellfish bed and taken to the Centre of Technological Innovation of Edification and Civil Engineering (CITEEC) at the University of A Coruña. The maximum dimension of the individuals was determined with a $0.1-\mathrm{mm}$ precision gauge and each one was labelled with nail polish. Once the paint had dried, the molluscs were placed inside a 240-L aquarium with filtered and aerated seawater at a temperature of $14^{\circ} \mathrm{C}$. Marine microalgae Tetraselmis suecica was used to feed the molluscs daily. The seawater and the cockles were renewed weekly to reduce the influence of mollusc activity on the results. In order to analyse possible effects of cockle activity on the erosion processes, live and dead individuals of the same size were tested. The cockles of each size were preserved in a formalin-based solution $(1 \%)$ prior to their use during the experiments.

\section{Flume description}

The experimental study was carried out in a custommade stainless steel recirculation racetrack flume at the CITEEC. The flume has two straight alignments of 1.2 $\mathrm{m}$ and a total length of approximately $9.5 \mathrm{~m}$ (Fig. 2). The channel is $50 \mathrm{~cm}$ wide and the water depth was maintained during the experiments at $15 \mathrm{~cm}$, therefore holding a width:depth aspect ratio of 3.3. Similar ratios, ranging from 2.16 to 5 , can be found in other benthic racetrack flume experiments (e.g. de Montaudouin et al. 2003, Hunt 2004, St-Onge and Miron 2007, Redjah et al. 2010). The water flow was generated by the friction of 10 vertical rotating discs with a radius of $28 \mathrm{~cm}$ each. The rotation of the discs was controlled by a $24-\mathrm{V}$ DC motor $(134 \mathrm{~W}, 98 \mathrm{rpm})$. In order to reduce the cornerflow effects and the development of hydraulic artifacts, a series of parallel walls were installed along the semicircular sections. The experimental section, a 70x40x10 $\mathrm{cm}$ box, was placed in front of the discs and filled with sand collected from the study area, with an average diameter of $0.98 \mathrm{~mm}\left(\mathrm{~d}_{50}=1.42 \mathrm{~mm}\right)$. The organic matter content of the sand, determined according to the ASTM Standard D-2974 (2007), was less than 1\%. The salinity during the flume tests was set at $35 \mathrm{ppt}$, while the seawater temperature ranged from $17^{\circ} \mathrm{C}$ to $19^{\circ} \mathrm{C}\left(18.3 \pm 0.5^{\circ} \mathrm{C}\right)$.

Racetrack flumes are commonly used for biological benthic channel experiments. The flume tanks tend 
A

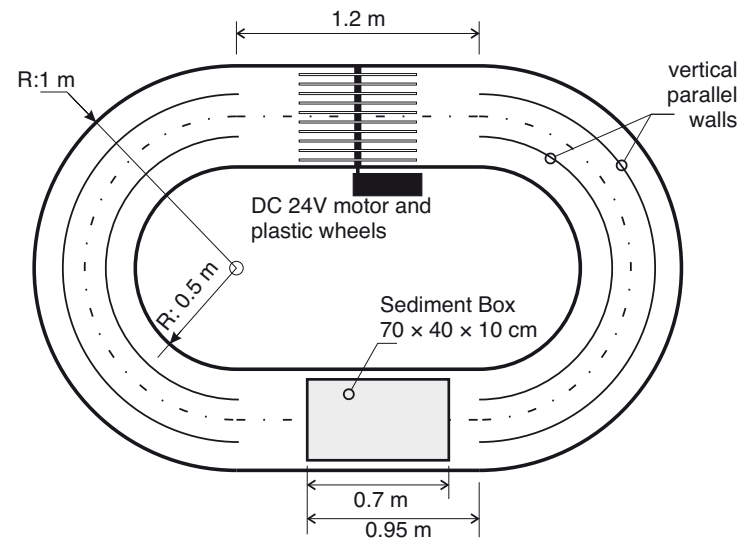

Area of analysis
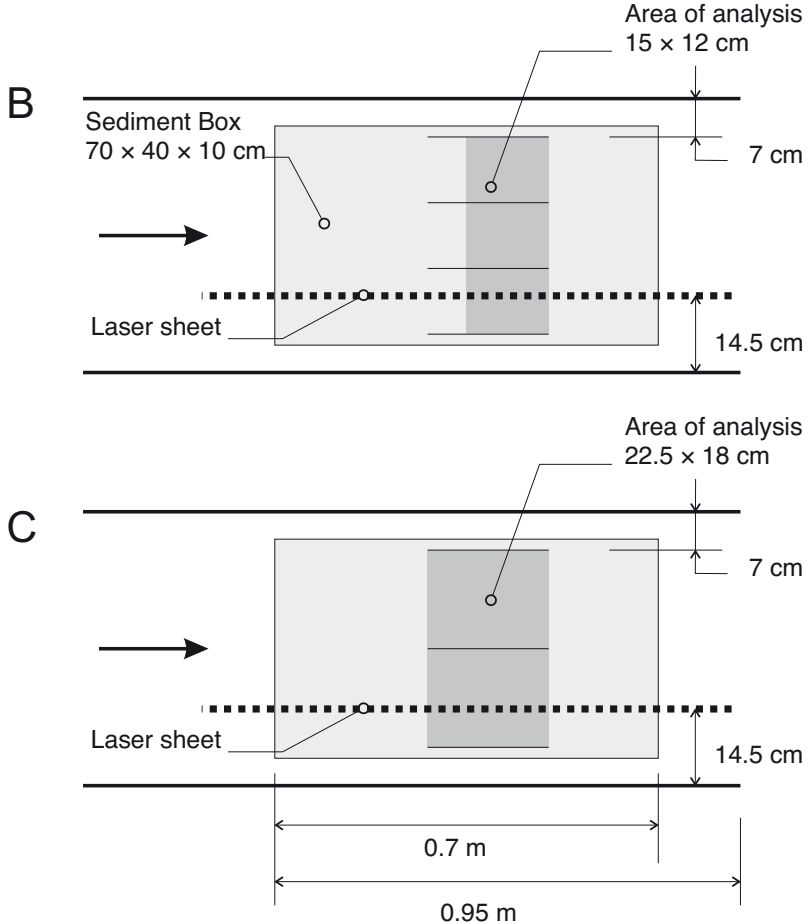

FIG. 2. -Layout of the racetrack flume used to carry out the experiments (A) and experimental setup for the size class (B) and natural distribution experiments (C).

to compromise between hydrodynamical optimization on the one hand, and practical and financial constraints on the other (Jonsson et al. 2006). For instance, the regulation of temperature and salinity conditions or feeding supply is only affordable in small flumes (i.e. volume $<1-2 \mathrm{~m}^{3}$ of salty water). In racetrack flumes, two phenomena may affect the development of 2D uniform straight flows. The first is the generation of a jet-like flow by the disc pump and the second is the above-mentioned existence of secondary motions (Piedra-Cueva et al. 1997). Centrifugal forces due to the flume's curvature and the width:depth aspect ratio generated secondary currents which contributed to cross-channel variations in flow velocities and shear stresses. This secondary current transported momentum from the side wall towards the channel centre. The downflow occurring along the channel centreline shifts the position of the maximum streamwise velocity below the water surface, inducing the velocity dip phenomenon (Nezu and Nakagawa 1993). The effect of the secondary currents on the velocity distribution found in our experiments is analysed later in the Results section.

\section{Experimental setup}

The erosion of the Cerastoderma edule cockle was examined using two different procedures called "size class" and "natural distribution" experiments. Since we focused on the cockle dispersal recorded at the study site in stormy conditions, in both experimental procedures we aimed to reproduce the same size range as that found at the Lombos do Ulla during these events. In the size class experiments, the cockles were classified into four groups (15-20, 20-25, 25-30 and 30$35 \mathrm{~mm}$ ) with an approximately uniform distribution: $17.8 \pm 1.6,22.3 \pm 1.8,27.6 \pm 1.6$ and $31.9 \pm 1.5 \mathrm{~mm}$ (mean \pm standard deviation of the cockle width). In the natural distribution tests, the cockle size distribution was much broader, with shell lengths ranging from 10 to $32 \mathrm{~mm}$. Using the shellfish bed data available from Parada et al. (2006), two groups were assigned with mean cockle widths of 20.9 and $24.5 \mathrm{~mm}$. Cockle size distribution for natural distribution tests are shown in Figure 3.

In the natural distribution experiments, we specifically considered whether a broad size distribution could affect the transport ratios of large cockles, as occurs with sediment mixtures. Graded sediments can reduce the transport rate of fine grains and increase that of coarser particles in comparison with the rates measured in uniform sediments with an equivalent mean diameter. This is due to the hiding and overexposing effect on the smaller and larger sizes of the mixture and is usually referred to as bed armour in alluvial stream hydraulics (see elsewhere, e.g. Parker 1990).

The gradation of the sediment and cockle mixtures can be described using the gradation coefficient (Julien 2002):
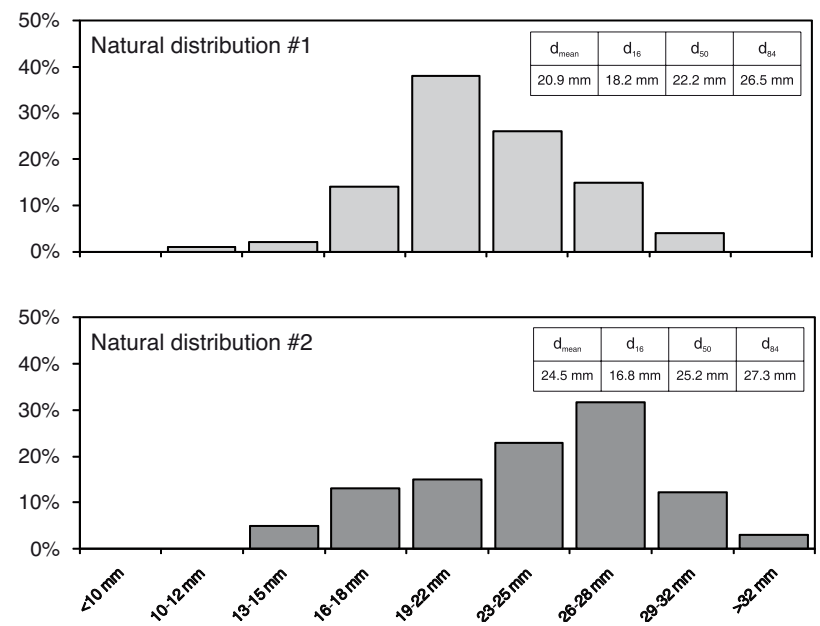

FIG. 3. - Size distribution and characteristic widths of the cockles in the natural distribution tests. 


$$
G r=\frac{1}{2}\left(\frac{d_{84}}{d_{50}}+\frac{d_{50}}{d_{16}}\right)
$$

where $d_{16}, d_{50}$ and $d_{84}$ are the sediment sizes for which $16 \%, 50 \%$ and $84 \%$ by weight of the material is finer, respectively. The gradation coefficient falls to unity for uniform sediment mixtures, such as $\mathrm{d}_{16} \sim \mathrm{d}_{50} \sim \mathrm{d}_{84}$, but increases with nonuniformity.

The gradation coefficient for the natural sand substrate is about 1.9, which corresponds to a uniform to graded mixture. Size class populations have a gradation coefficient that is almost unity $(\sim 1.05)$, while the natural distributions show some nonuniformity. For the populations with mean cockle widths of 20.9 and $24.5 \mathrm{~mm}$, the gradation coefficients are $\sim 1.2$ and $\sim 1.3$, respectively.

For each size class and natural distribution group, different trials with two population densities and cockle activities (live vs dead) were also analysed. Two densities of 500 ind $\mathrm{m}^{-2}$ and 1000 ind. $\mathrm{m}^{-2}$ were selected from the study site data. The erosion experiments were conducted under six different velocities ranging from 0.29 to $0.47 \mathrm{~m} \mathrm{~s}^{-1}$ and covering the expected adverse flow velocities found in the shellfish bed (see measurement details in the following sections). As summarized in Table 1, the experimental design was factorial, analysing 4 sizes $\times 6$ velocities $\times 2$ population densities $\times$ 2 activities, 96 scenarios, with 4 repetitions for the size class experiments; and 2 distributions $\times 6$ velocities $\times 2$ densities $\times 2$ activities, 48 scenarios, with 3 repetitions for the natural population trials.

The bivalves were placed into two $15 \times 12 \mathrm{~cm}$ and $22 \times 18 \mathrm{~cm}$ cells for the size class and populations tests, respectively (Fig. 2). The different experimental enclosures were separated by a steel plate embedded in the sand and protruding about $3 \mathrm{~cm}$. These plates were the same characteristic height as the analysed cockles so their interference with the flow was negligible. The plates were used to avoid interactions between organisms of different regions and with the experimental velocimetry technique (see next section).

Prior to each experimental run, the sand was levelled. Then, the cockles were randomly placed on the bed by hand, with the shell opening facing the current. The size distribution in the different compartments was also randomly chosen to avoid the effect of position on the erosion of the cockles. Before the experiments, the cockles were given an acclimation period of 10 minutes to adapt to the flume environment. With this procedure we aimed to reproduce the surficial position and the emergence patterns of the cockles described by Richardson et al. (1993) for high density patches of Cerastoderma edule cockles during sporadic storm-induced sediment transport. Thus, our experimental conditions were defined to avoid cockle burial in the sand as we intended to reproduce bivalve erosion under flood conditions.

To select the time length of the experimental runs, a series of long preliminary tests (30 minutes) were
TABLE 1. - Summary of the factors analysed during the experiments.

\begin{tabular}{lll}
\hline Experiment & Treatment & Factor \\
\hline Size class & Mean velocity & $0.29,0.31,0.35,0.39$, \\
& Cockle distribution & 0.44 and $0.47 \mathrm{~m} \mathrm{~s}^{-1}$ \\
& and $30-25,25-30$ \\
& Cockle density & 500 and 1000 ind. $\mathrm{m}^{-2}$ \\
& Cockle activity & Live / Dead \\
Natural distribution & Mean velocity & $0.29,0.31,0.35,0.39$, \\
& & 0.44 and $0.47 \mathrm{~m} \mathrm{~s}^{-1}$ \\
& Cockle distribution & 20.9 and $24.5 \mathrm{~mm}^{-2}$ \\
& Cockle density & 500 and 1000 ind. $\mathrm{m}^{-2}$ \\
& Cockle activity & Live / Dead \\
\hline
\end{tabular}

conducted for the size class and natural distribution arrangements. After approximately 5 and 10 minutes, respectively, no significant increase in the number of eroded molluscs was found in the size class or natural population tests, respectively. Following these preliminary results, the length of the erosion runs was set at 5 and 10 minutes for each experimental procedure. Once each trial was completed, the motor was turned off and the swept molluscs were counted.

\section{Flow characterization}

The PIV technique was used to determine velocity fields over the cockle patches. The Lavision $($ e equipment consists of two Nd:Yag laser sources, a 1-Mpx camera, a frame grabber and the Davis 7.2 control and evaluation software. A total of 500 images were recorded during each experiment at a data rate of 3.33 $\mathrm{Hz}(150 \mathrm{~s})$. Image evaluation was carried out using an iterative multi-grid interrogation scheme $\left(128 \mathrm{px}^{2}\right.$ to 32 $\mathrm{px}^{2}$ ) with a $75 \%$ overlap. A deformable window algorithm was applied to the 32- $\mathrm{px}^{2}$ interrogation window. Prior to the application of the cross-correlation technique, raw images were pre-processed with a sliding background and a min/max filter. The velocity fields were then post-processed using a local median filter (Westerweel 1994) with a 3-RMS threshold. The preand post-processing methodology reduced the number of spurious vectors, increasing the accuracy of the PIV technique. The spatial resolution of the image is $4 \mathrm{px} /$ $\mathrm{mm}$, and approximately $\sim 2 \mathrm{~mm}$ for velocity measurements. A conservative value for the relative error of the pixel displacement is $2 \%$ (Raffel et al. 2007). In our measurements a mean displacement of $4 \mathrm{px}$ was found, the systematic error being about $\sim 0.02 \mathrm{~mm} \mathrm{~s}^{-1}$. The random error of the mean velocity can be evaluated under normal and uncorrelated sample assumptions. For a confidence interval of $95 \%$, this error equals 1.96 $\sigma_{u} / \sqrt{ } N$, where $\sigma_{u}$ is the standard deviation of the velocity calculated from $\mathrm{N}=500$ samples. The characteristic maximum standard deviation is $\sim 15 \mathrm{~cm} \mathrm{~s}^{-1}$, so the random error is estimated at $13 \mathrm{~mm} \mathrm{~s}^{-1}$, which is clearly the main contribution to the total error.

The flow's properties were measured at a vertical plane, $10.5 \mathrm{~cm}$ away from the flume centreline (Fig. 2). The measuring position was selected according to 
flow visualization criteria. The velocity fields were determined with and without molluscs, or "flat bed" experiments. The latter values were used to compare flow characteristics on cockle patches and sand beds. For the erosion tests, the presence of the cockle patches would enhance bed roughness, making the flow spatially heterogeneous. In this context, it was difficult to define flow properties such as representative velocity profiles or their origin of coordinates. For the proper assessment of the hydrodynamics, especially in the near-bed regions, both temporal and spatial flow fluctuations had to be considered. In order to do this, we applied the double-averaged (DA) methodology, which consists in the spatial and temporal averaging of the hydrodynamic variables within thin slabs parallel to the mean bed position. Fundamentals of the DA method can be found in Nikora et al. (2007) and are also summarized in Anta et al. (2013).

With this procedure we determined the double (spatial and temporal) averaged velocity profile and the shear velocity $u_{*}$. The shear velocity characterizes the bottom shear stress and is therefore typically used as a convenient velocity parameter to describe nearbottom flow (Nowell and Jumars 1984). To determine the shear velocity over the cockle patches, the log-law for hydraulic rough flows was used:

$$
\langle\bar{U}(z)\rangle=\frac{u_{*}}{\kappa} \ln \frac{z}{z_{0}}
$$

where $\langle\bar{U}(z)\rangle$ represents the horizontal velocity doubleaveraged to the height $z, \kappa$ is the von Kármán constant $(\sim 0.41)$ and $z_{0} \mathrm{k}$ is the characteristic bottom roughness. In order to obtain the $u_{*}-z_{0}$ pairs, Equation (2) was adjusted over the log-linear stretch above the bed crest and below a height of $0.2 \cdot H$ with a least squares method.

From the sand's properties and bottom shear velocity, the Shield parameter $\Theta$ was determined. This parameter is traditionally used to describe the threshold of movement for non-cohesive sediments and is defined as:

$$
\Theta=\frac{u_{*}^{2}}{\sqrt{g d_{m}}}
$$

where $\Delta$ represents the specific density of the sediment minus one, $\rho_{s} / \rho-1 \sim 1.65, g$ the gravitational acceleration and $d_{m}$ the medium diameter of the sediment.

\section{Statistical analysis of erosion rates}

The main effects of mean velocity, cockle size, density and activity (live vs dead), as well as their interaction, were analysed using the erosion rates as the dependent variable in a four-way factorial ANOVA. The number of eroded cockles was $\arcsin \sqrt{\mathrm{x}}$-transformed to obtain the homogeneity of variances, as determined by the Cochran test with a significance level $\alpha=0.05$ (Underwood 1997). All the factors were fixed. The
A

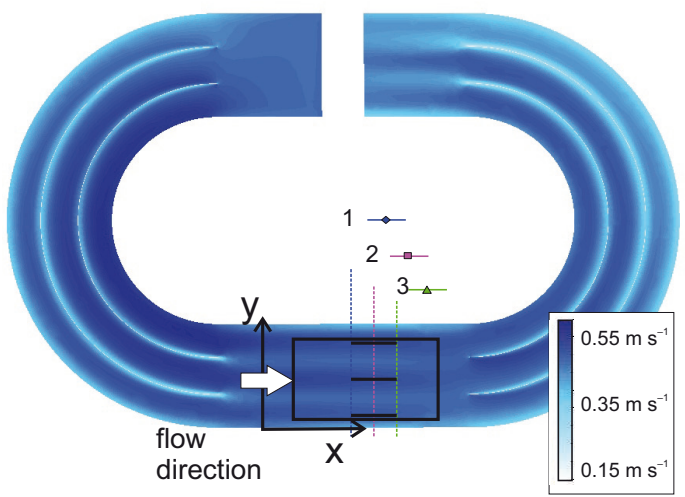

B

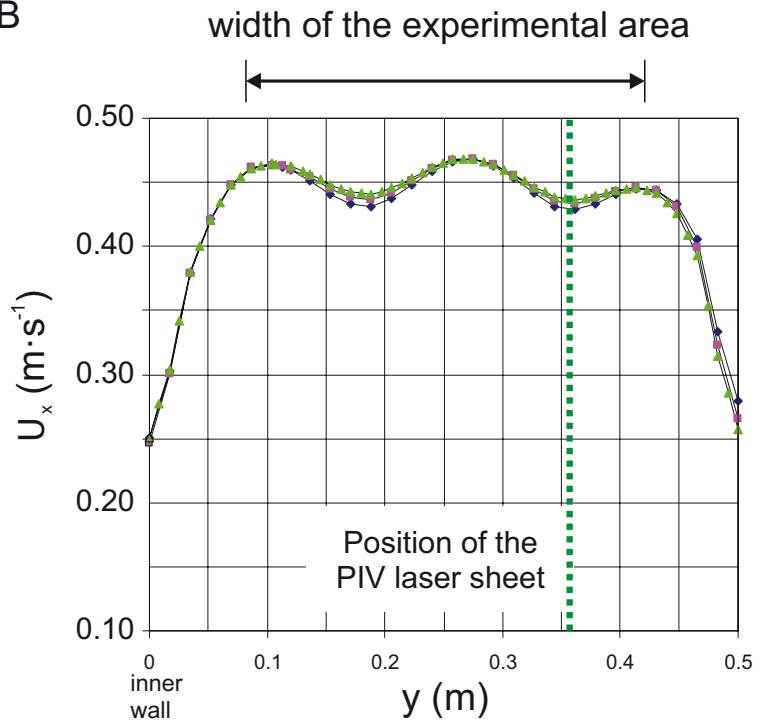

FIG. 4. - Numerical simulation of the racetrack flume: velocity map distribution (A) and velocity profiles over the experimental area (B). Mean flow velocity of $0.45 \mathrm{~m} \mathrm{~s}^{-1}$. The simulations were developed with the $k-\varepsilon$ turbulence closure model.

significance of velocity and size levels was analysed with the post hoc Student-Neuman-Keuls (SNK) comparison test. These tests were carried out using SPSS (C) v17 and Microsoft Excel 2003@ software.

\section{RESULTS}

\section{Flow characterization}

The flow developed in curved channels is characterized by the presence of transversal velocity gradients associated with secondary currents. These secondary currents are especially important in annular flumes. In racetrack flumes, the straight working section provides hydrodynamic conditions which closely resemble 2D boundary layer properties with almost negligible transversal velocity gradients. Some experimental works have characterized the cross-sectional features of the flow in racetrack flumes, finding shear velocity variations of about $10 \%$ of the average cross-sectional values for $70 \%-80 \%$ of the central part of the flume (Black 


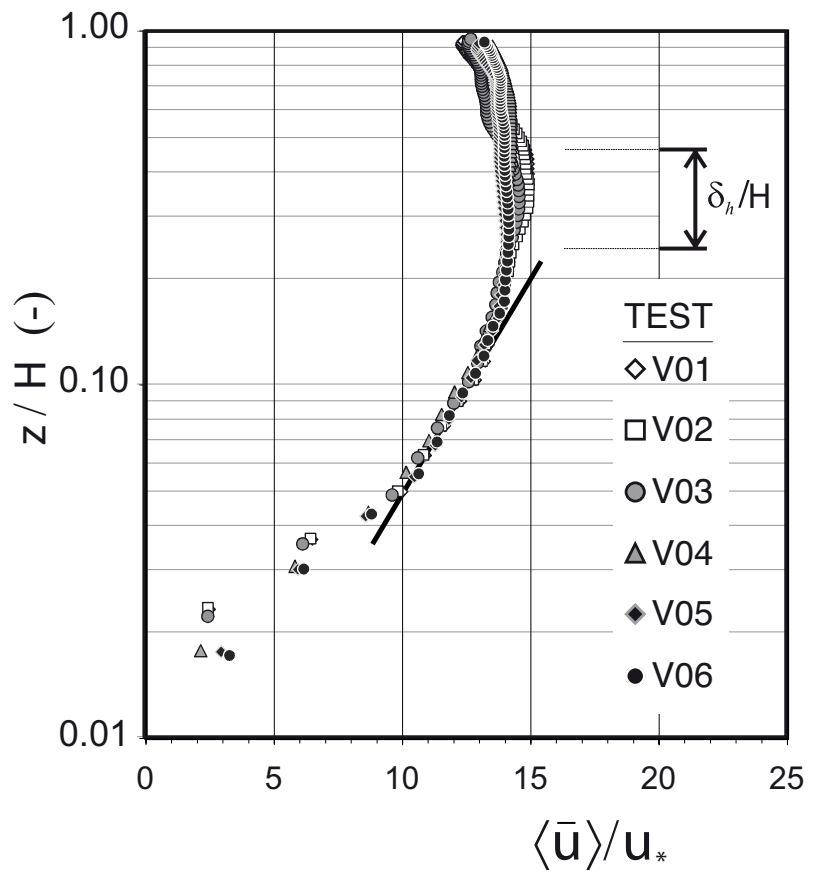

FIG. 5. - Double-averaged streamwise velocity profiles for the flat bed experiments.

and Cramp 1995, Piedra-Cueva et al. 1997, Redjah et al. 2010). Unfortunately, we were not able to measure the transversal flow variability because of the optical constraints of the PIV experimental design. However, an indirect assessment was performed by the numerical simulation of the racetrack flume using a 2D shallow water code (Cea et al. 2007). The results obtained show small cross-sectional variations of about $10 \%$ of the averaged streamwise velocities, which agree with the experimental works in the literature (Fig. 4).

An accurate description of the velocity fields and double-averaged velocity profiles was accomplished by means of the PIV technique. Regarding the velocity profiles, for the flat bed experiments we obtained a reasonable collapse of the streamwise component in the logarithmic region, $z / H<0.20$ (Fig. 5). As found in other racetrack flume flows (Piedra-Cueva et al. 1997), the position of the maximum velocity $\delta_{h}$, is shifted downwards from the water surface towards the bed. The maximum velocity is reached for a relative position $\delta_{h} / H$ of $0.38 \pm 0.08$ (mean \pm sd).

Table 2 shows both depth-averaged profiles $\langle\bar{U}\rangle$ and shear velocity $u_{*}$ for flat bed and size class experi-

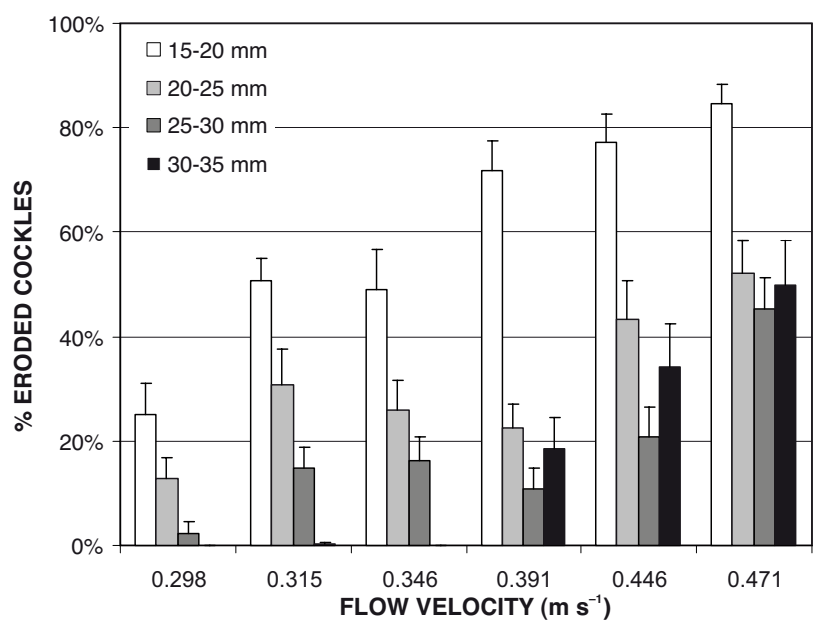

FIG. 6. - Percentage of eroded cockles (mean \pm se, $n=16$ ) for different shell sizes and flow velocities in size class experiments (population densities and cockle activity are pooled)

ments. In the flat bed trials, shear velocity increases with flow velocity and roughly represents 5\%-10\% of the flow's mean velocity, which is consistent with the empirical values found for alluvial flows. Naked eye observations during the experiments show that sediment bedload begins between the second and third velocity step, which corresponds with Shields parameter $\Theta$ ranging from 0.030 to 0.056 . These values agree quite well with the threshold of bedload movement for sand particles (Buffington and Montgomery 1997).

In the cockle erosion experiments, velocity profiles are affected by the presence of the bivalve patches. In this case the velocity dip position depends on cockle size and population density. In the size class experiments, the mean $\delta_{h} / H$ position ranges between $0.36 \pm 0.17$ to $0.31 \pm 0.16$ for classes from $15-20 \mathrm{~mm}$ to $30-25 \mathrm{~mm}$. The maximum velocity is closer to the bed as the density decreases $\left(\delta_{h} / H=0.37 \pm 0.21\right.$ and $0.30 \pm 0.35$ for high and low populations respectively), showing the effect of the roughness introduced by the cockle patches in the flow structure.

The shear velocities are on average higher than those obtained for flat bed conditions, $44 \% \pm 21 \%$ and $42 \% \pm 10 \%$ (mean \pm sd) for size classes and natural distribution, respectively. Generally, the determined shear velocities are roughly proportional to mean flow velocity, although size class trials do show a decrease within the second and fourth current velocity step (Table 2). The reduction in the bottom shear stress is

TABLE 2. - Summary of average mean velocity $U$ and shear velocity $u_{*}$ (mean \pm sd) in flat bed (FB) and size class (SC) tests (cockle activity and density are pooled).

\begin{tabular}{lcccccc}
\hline Index & & FB & \multicolumn{3}{c}{$\mathrm{SC}-\mathrm{u}_{*}\left(\mathrm{~cm} \mathrm{~s}^{-1}\right)$} \\
& $\mathrm{U}\left(\mathrm{cm} \mathrm{s}^{-1}\right)$ & $\mathrm{u}^{*}\left(\mathrm{~cm} \mathrm{~s}^{-1}\right)$ & $15-20 \mathrm{~mm}$ & $20-25 \mathrm{~mm}$ & $25-30 \mathrm{~mm}$ & $30-35 \mathrm{~mm}$ \\
\hline V01 & 29.4 & 2.28 & $3.4 \pm 0.5$ & $3.3 \pm 0.2$ & $4.2 \pm 0.4$ & $4.0 \pm 0.4$ \\
V02 & 31.5 & 2.34 & $3.9 \pm 0.2$ & $4.1 \pm 0.5$ & $4.1 \pm 0.4$ & $3.3 \pm 0.3$ \\
V03 & 34.6 & 2.62 & $4.6 \pm 0.7$ & $3.9 \pm 0.3$ & $5.3 \pm 0.4$ & $4.1 \pm 0.4$ \\
V04 & 39.1 & 3.05 & $3.4 \pm 0.1$ & $4.5 \pm 0.5$ & $4.1 \pm 0.4$ & $5.4 \pm 0.7$ \\
V05 & 44.6 & 3.46 & $3.7 \pm 0.7$ & $4.3 \pm 0.3$ & $5.5 \pm 0.9$ & $5.4 \pm 0.8$ \\
V06 & 47.1 & 3.63 & $3.7 \pm 0.3$ & $4.4 \pm 0.5$ & $5.0 \pm 0.7$ & $3.9 \pm 0.1$ \\
\hline
\end{tabular}


TABLE 3. - Summary of the four-way ANOVA for the factorial design carried out on the mean proportion of eroded cockles for size class trials. $* \mathrm{p}<0.05 ; * * \mathrm{p}<0.005$ and $1-\beta>0.75(\alpha=0.05)$.

\begin{tabular}{|c|c|c|c|c|c|c|}
\hline Source of variation & SS & Df & MS & $\mathrm{F}$ & $\mathrm{p}$ & $1-\beta$ \\
\hline Velocity (V) & 18.566 & 5 & 3.713 & 52.750 & $<0.001 * *$ & $>0.999$ \\
\hline Size (SZ) & 22.879 & 3 & 7.626 & 108.338 & $<0.001 * *$ & $>0.999$ \\
\hline Density (DEN) & 1.971 & 1 & 1.971 & 28.000 & $<0.001 * *$ & $>0.999$ \\
\hline Activity: Live/ Dead (ACT) & 1.144 & 1 & 1.144 & 16.258 & $<0.001 * *$ & 0.980 \\
\hline $\mathrm{V} \times \mathrm{SZ}$ & 3.591 & 15 & 0.239 & 3.401 & $<0.001 * *$ & 0.999 \\
\hline $\mathrm{V} \times \mathrm{DEN}$ & 0.631 & 5 & 0.126 & 1.794 & 0.114 & 0.612 \\
\hline $\mathrm{V} \times \mathrm{ACT}$ & 0.137 & 5 & 0.027 & 0.389 & 0.856 & 0.151 \\
\hline $\mathrm{SZ} \times \mathrm{DEN}$ & 0.323 & 3 & 0.108 & 1.531 & 0.207 & 0.403 \\
\hline $\mathrm{SZ} \times \mathrm{ACT}$ & 0.607 & 3 & 0.202 & 2.875 & $0.037 *$ & 0.684 \\
\hline $\mathrm{DEN} \times \mathrm{ACT}$ & 0.435 & 1 & 0.435 & 6.180 & $0.013 *$ & 0.698 \\
\hline $\mathrm{V} \times \mathrm{SZ} \times \mathrm{DEN}$ & 2.402 & 15 & 0.160 & 2.274 & $0.005 * *$ & 0.979 \\
\hline $\mathrm{V} \times \mathrm{SZ} \times \mathrm{ACT}$ & 1.798 & 15 & 0.120 & 1.703 & $0.050 *$ & 0.913 \\
\hline $\mathrm{V} \times \mathrm{DEN} \times \mathrm{ACT}$ & 0.568 & 5 & 0.114 & 1.614 & 0.156 & 0.559 \\
\hline $\mathrm{SZ} \times \mathrm{DEN} \times \mathrm{ACT}$ & 0.307 & 3 & 0.102 & 1.456 & 0.227 & 0.384 \\
\hline $\mathrm{V} \times \mathrm{SZ} \times \mathrm{DEN} \times \mathrm{ACT}$ & 1.744 & 15 & 0.116 & 1.652 & 0.060 & 0.902 \\
\hline ERROR & 20.273 & 288 & 0.070 & & & \\
\hline TOTAL & 182.563 & 384 & & & & \\
\hline
\end{tabular}

also followed by a decrease in the number of eroded cockles, as observed in Figure 6. For the same flow conditions, shear velocity increases with mollusc size and low population densities. Furthermore, size class trials show larger values than natural distribution experiments (Anta et al. 2013).

\section{Erosion rates}

The ANOVA results for the size class experiments point out that all the analysed factors significantly affect the mollusc's mobilization (Table 3). Furthermore, there are five significant interactions which hinder a global interpretation of the results, as the post hoc tests should not be developed on the main effects. Three significant first order interactions appear: size $x$ velocity, which will be discussed below, and size $x$ activity and density $\times$ activity, which have a low statistical power (e.g. $1-\beta<0.75$ ). The two second order interactions indicate that the experimental velocity $\times$ size treatment does not operate independently for any population density or activity combination. An example of the post hoc SNK tests for the complex third order interactions is presented in the Appendix 1 , showing that velocity $\times$ size $\times$ density experimental treatments are interdependent and have a high nonlinear behaviour.

Due to the difficulty of extracting general information about the later analysis of the interactions, we
TABLE 4. - Percentage of eroded cockles (mean \pm se) for different population densities and activities in both size class and natural distribution tests.

\begin{tabular}{llcc}
\hline Factor & & $\begin{array}{c}\text { Size-class } \\
\text { experiments } \\
(\mathrm{N}=144)\end{array}$ & $\begin{array}{c}\text { Natural distribution } \\
\text { experiments } \\
(\mathrm{N}=96)\end{array}$ \\
\hline Cockle density & 500 ind. $\mathrm{m}^{-2}$ & $37.0 \% \pm 2.2 \%$ & $34.9 \% \pm 4.8 \%$ \\
& 1000 ind. $\mathrm{m}^{-2}$ & $26.3 \% \pm 2.3 \%$ & $24.0 \% \pm 1.6 \%$ \\
Cockle activity & Live & $27.8 \% \pm 4.5 \%$ & $29.6 \% \pm 8.4 \%$ \\
& Dead & $35.5 \% \pm 2.2 \%$ & $29.3 \% \pm 1.7 \%$ \\
\hline
\end{tabular}

also carried out SNK tests on the main factors. We must note that due to interactions the reliability and generality of the post hoc is limited. Concerning the main factors, the tests did not show significant differences for velocities between $\sim 0.3$ and $\sim 0.4 \mathrm{~m} \mathrm{~s}^{-1}$ and in the number of eroded cockles in the two largest size classes (25-30 and 30-35 mm). Overall, mobilization becomes more frequent as velocity increases and size decreases (Fig. 6). Table 4 shows the erosion rates averaged within the main factors of density and activity. On average, cockle transport is higher in patches with lower densities and dead molluscs.

For natural distribution experiments, the four-way factorial ANOVA showed that cockle activity did not affect erosion or any other significant interaction (results not shown). Consequently, the activity was pooled in the analysis (Underwood 1997) and a threeway ANOVA was re-conducted (Table 5). All remain-

TABLE 5. - Summary of the three-way ANOVA for the factorial design carried out on the mean proportion of eroded cockles for natural population trials. ${ }^{*} p<0.05 ;{ }^{* *} p<0.005$ and $1-\beta>0.75(\alpha=0.05)$.

\begin{tabular}{lrrrrrr}
\hline Source of variation & \multicolumn{1}{c}{ SS } & Df & MS & F & p & $1-\beta$ \\
\hline Velocity (V) & 8.514 & 5 & 1.703 & 84.871 & $<0.001^{* *}$ & $>0.999$ \\
Size (SZ) & 0.262 & 1 & 0.262 & 13.069 & $<0.001^{* *}$ & 0.948 \\
Density (DEN) & 0.670 & 1 & 0.670 & 33.399 & $<0.001^{* *}$ & $>0.999$ \\
V×SZ & 0.083 & 5 & 0.017 & 0.828 & 0.532 & 0.289 \\
V×DEN & 0.097 & 5 & 0.019 & 0.963 & 0.443 & 0.334 \\
SZ $\times$ DEN & 0.011 & 1 & 0.011 & 0.543 & 0.462 & 0.113 \\
V $\times$ SZ $\times$ DEN & 0.140 & 5 & 0.028 & 1.392 & & 0.477 \\
ERROR & 2.408 & 120 & 0.020 & & & \\
TOTAL & 54.053 & 144 & & & & \\
\hline
\end{tabular}




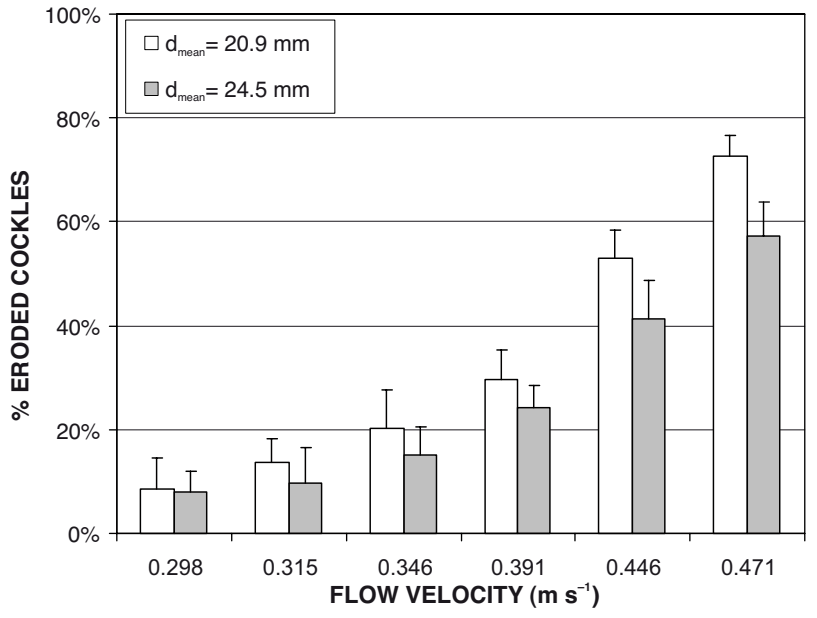

FIG. 7. - Percentage of eroded cockles (mean \pm se, $n=12$ ) for different shell size distributions and flow velocities for natural population trials (population densities and cockle activity are pooled).

ing factors tested in these trials affect the cockle's dispersal without any significant interaction. Regarding the post hoc tests, the SNK test on the velocity factor found significant differences for all velocities, except the two lower ones.

As for size class tests, the amount of eroded cockles was higher for the 500 ind. $\mathrm{m}^{-2}$ density (Table 4). Thus, in the analysed density range and under the same flow conditions, an inverse relationship was observed between population density and shear velocity (Anta et al. 2013), which explains why erosion rates are higher for lower densities in both size class and natural distribution experiments. Furthermore, contrary to the size class trials, the percentage of eroded cockles in the natural population experiments is independent of the bivalve activity (Table 4 ).

An inverse relationship was found between flow velocity and the number of swept molluscs (Fig. 7). This relationship is monotonic for the natural distribution trials although in the size class trials a reduction in the erosion rates was observed between velocities of 0.31 and $0.39 \mathrm{~m} \mathrm{~s}^{-1}$, which correspond roughly to the Shields shear stress $\Theta$ for the sediment threshold of movement. Therefore, sand bedload buries the molluscs, thus reducing their vulnerability to being eroded. This phenomenon takes place at $0.35 \mathrm{~m} \mathrm{~s}^{-1}$ for $15-20$ $\mathrm{mm}$ and 20-25 mm size classes, whereas in the 25-30 $\mathrm{mm}$ class it appears at $0.39 \mathrm{~m} \mathrm{~s}^{-1}$, probably because larger bivalves take longer to be buried by the bedload motions (Fig. 6). The ANOVA test performed in the size-class experiment also captures this interaction between size and velocity. For higher velocities, erosion rates increase once again because the cockles are swept faster and not trapped by the sand.

It is also noteworthy that the natural distribution groups show a higher resistance to the flow for lower velocities than their equivalent homogeneous size class. For $0.35 \mathrm{~m} \mathrm{~s}^{-1}$ the percentage of eroded 20-25 $\mathrm{mm}$ cockles is $30 \%$ compared with only $10-14 \%$ in population trials. For higher velocities, this effect disappears and the erosion rates match. This behaviour is similar to the bedload transport of non-uniform sediments. In sediment mixtures, the coarse particles are more easily eroded than uniform sediment with the equivalent size because they are more exposed to the flow. The fine particles of the mixture are sheltered by the coarse particles and therefore their behaviour is the opposite.

In order to quantify this effect in alluvial channels, the following relationship between the threshold shear stress for the different sediment diameters of the mixture can be applied (Parker 1990, García 2006):

$$
\tau_{b, i}=\tau_{b, j}\left(\frac{d_{i}}{d_{j}}\right)^{1-\beta}
$$

where $\tau_{b, i}$ and $\tau_{b, j}$ denoted the values of the critical shear stress required to move sediment of sizes $d_{i}$ and $d_{j}$ in the mixture, respectively, and $\beta$ is an exponent which is 0 for uniform sediment mixtures and $\sim 0.9$ for graded sediment mixtures.

Although this equation was developed for gravel transport in rivers, it can be applied in some way to the cockle distributions to assess the effect of the cockle gradation in the natural population trials. For example, let us suppose two cockle distributions with diameters of $\sim 26.5 \mathrm{~mm}$ and $\sim 18 \mathrm{~mm}$ (which roughly correspond to the characteristic diameters $d_{84}$ and $d_{16}$ of natural distribution \#1). If the two distributions are uniform, it follows from Equation (4) that the critical stress for coarser material is 1.5 times that of the finer material, which is the ratio between the two diameters involved in the analysis. In a cockle mixture, however, the critical shear stress for the large bivalves is only about $1.5^{0.1} \sim 1.04$ times that for the smaller cockles. Thus, a finer particle in a mixture is only slightly more mobile than its brethren of coarser size, and much more easily eroded than uniform particles with the same size (García 2006).

\section{DISCUSSION}

The current speeds and cockle population size, distributions and densities which were used in the erosion experiments are similar to those found at Lombos do Ulla during the dispersal episodes related to severe storm events. The experimental setup reproduces the hydrodynamic and environmental conditions during these situations and the obtained erosion rates allow us to improve the knowledge on the erosion and transport of the cockle stocks in this scenario.

To quantify the interaction between the soft-bottom invertebrate structure and passive dispersal, it is necessary to measure simultaneously both near-bed hydrodynamics and transport ratios, which also depend on the organism's size and distribution. Most of the flume experiments performed to analyse the erosion of larva 
and juvenile bivalves have not paid much attention to this issue, mainly because of the small size of the tested individuals and/or because the organisms were previously buried (e.g. Roegner et al. 1995, de Montaudouin 1997, Hunt 2004, St-Onge and Miron 2007, Jennings and Hunt 2009, Redjah et al. 2010). Under these circumstances, the flows can be considered as hydraulically smooth and interactions between organisms and near-bottom hydrodynamics are negligible.

However, in rough flows point or profile velocity measurements are not very informative due to the spatial variability of the bed. This is especially true of near-bed roughness, which increases local turbulence. Ciutat et al. (2007) reported "erratic profiles and variability in the data" around the cockles tested in their sediment erosion tests in an annular flume and a muddy substrate. To avoid this problem, we applied the DA methodology to the PIV velocity field measurements to successfully characterize the double-averaged mean velocity and the shear velocities over the sand and cockle beds. This procedure allowed us to determine the difference in erosion rates according to parameters such as size distribution and population density of the molluscs on the bed.

The results of our study show a strong interaction between of all the factors analysed: flow, size and distribution of the molluscs and their population density. Other aspects that presumably might influence the erosion are sediment and organism type, burrowing behaviour and burial depth of the individuals (e.g. StOnge et al. 2007, Redjah et al. 2010). However, our experimental conditions were not intentionally favourable to cockle burial and the cockles were placed over the sand bed as we aimed to reproduce both the highdensity and storm-emergence patterns described above.

Cockle size plays an important role in the erosion process, with increasing erosion rates at high flow velocities. In the size class experiments, a drop in the number of eroded molluscs was reported for flow velocities corresponding to the threshold of motion of the sediment bed. In addition to cockle size and distribution, the population density of the bivalves can also be considered as a surrogate of the bed roughness structure. In rough flows, the local structure of the near-bed flow is mainly conditioned by the size and separation of the bed roughness structures, such as the cockles, which determine the shear stresses over the bottom (Jiménez 2004), and therefore the erosion capacity of the flow. Thus, cockle patch density may enhance sediment erosion and bed roughness, as stated by Ciutat et al. (2007).

In our experiments, for the same free stream velocity the percentage of eroded cockles and shear velocities are usually larger for the low-density patches. This is due to the shape of the bottom, which is more heterogeneous and abrupt in the low-density arrangements. In this configuration, the streamlines adapts to the cockle gaps and the shear production is greater. In the high-density patches cockle separation is much smaller and the flow structure is similar to quasi-smooth or skimming flows (Anta et al. 2013).

Distribution also affects the transport of the adult stocks of cockles. The differences found between size class and natural population trials are similar to those found when analysing the transport of two sediment mixtures with the same mean diameter but different size distributions. As found in bed armouring phenomena in graded sediment, in the tested broad natural cockle distributions the smaller individuals are less exposed to the flow as they tend to hide in the lee of the large cockles. This hiding effect reduces their erosion rates in comparison with the uniform size class distributions. Therefore this "cockle armouring" phenomenon accounts for the slightly higher critical shear stress found in the natural distribution trials for the lower velocities. We must note that this process is different from the physical protection or armouring of the surface sediments by some bivalves (e.g. Widdows et al. 2002), which can also modify sediment transport ratios and organism dispersal due to the increase in bed roughness induced by the animal's density and feeding activity (e.g. Commito et al. 2005, van Duren et al. 2006).

Arguably, this conclusion might be biased because of the differences in the length of the erosion tests (twice those for natural distribution experiments). We fully acknowledge that with this experimental design the comparison of the two trials does not seem as direct, as one may expect a higher number of bivalves eroded in greater time. However, as stated above, the duration of the experiments was set according to the stabilization of the erosion process. Furthermore, we may also notice that the erosion rates behave oppositely, and a lower number of swept molluscs was recorded in the long natural distribution tests.

Cockles' activity may also affect their mobilization by means of active mechanisms such as the production of byssus thread or changes in their burrowing behaviour. In our experiments, the ANOVA tests highlight an increase in erosion in the dead size class experiments, while in the population trials this treatment was found to be insignificant. Due to the large size of the cockles, no byssus thread production was recorded, so the behavioural responses might be related to the burrowing capacity of the organisms during the acclimatizing phase previous to or during the trial. The lack of influence of the activity treatment on the natural distribution experiments could be due to the smaller differences in the cockle sizes between population distributions ( 21 to $25 \mathrm{~mm}$ ) and size class experiments (e.g. 15 to $35 \mathrm{~mm}$ ). Thus, burrowing capacity may also be related to mollusc size.

Another factor affecting the erosion processes of the cockles is the sediment size of the substrate. Under different substrate types (i.e. mud or gravel beds), changes in the erosion rates such as those reported by St-Onge and Miron (2007) can be expected. The differences may be attributable to changes in the friction co- 
efficient between the cockle shells and the sediments, and also to active mechanisms of substrate selection. Lastly, not only active mechanisms affect mobilization processes. As stated above, sediment bedload transport and its interaction with mollusc size and distribution may also be a determining factor for the passive dispersal of cockles.

Our flume experiments showed that a wide range of adult cockles may be eroded during high-flow events. These erosion rates could explain the sweeping episodes of the cockle stocks at the mouth of the River Ulla during high-flow events. Under these circumstances, a proper knowledge of the erosion and transport processes of the molluscs and of the hydrodynamic conditions of the estuary is essential in order to predict these dispersal events. Using the experimental data from this study, a bedload transport model for the natural distribution of the cockle population was developed by the authors using a conventional deterministic sediment transport framework (Anta et al. 2013). The formulas obtained are being implemented in a 2D shallow water code developed by the author's research team (Cea et al. 2007). The model is being applied to the Lombos de Ulla shellfish bed to assess the influence of river discharges on the erosion of adult cockle stocks. Some preliminary results can be found in Cea et al. (2010).

\section{ACKNOWLEDGEMENTS}

This study was supported by the Spanish Ministry of Environment (Project 113/SGTB/2007/1.4). We thank E. Martín and R. Losada for their help during the flume experiments, L. Cea for his support in the numerical simulations and J. Molares, A. Sanchez and P. Montero for their valuable comments on the Lombos do Ulla shellfish bed. We are also grateful for the support provided by the Santa Cristina Shellfishermen's Association, the Marine Research Centre at Corón, the Laboratory of Microbiology of the University of A Coruña and the Oceanographic Centre of A Coruña.

\section{REFERENCES}

Anta J., Peña E., Puertas J., Cea L. 2013. A bedload transport equation for the Cerastoderma edule cockle. J. Mar. Sys. 111-112: 189-195.

ASTM Standard D-2974, 2000. 2007. Standard Test Methods for Moisture, Ash, and Organic Matter of Peat and Other Organic Soils. American Society for Testing and Materials International, West Conshohocken, PA.

Buffington J.M., Montgomery D.R. 1997. A systematic analysis of eight decades of incipient motion studies, with special reference to gravel-beded rivers. Wat. Res. Res. 33: 1993-2029.

Cea L., Puertas J., Vázquez-Cendón M.E. 2007. Depth averaged modeling of turbulent shallow water flow with wet-dry fronts. Arch. Comput. Methods Eng. 14: 303-341.

Cea L., Anta J., Puertas J., Peña E. 2010. Implementation of a cockle habitat model in a two-dimensional shallow water model: application to a shallow estuary. In: Proceedings of Ist European IAHR. Edimburgh.

Ciutat A., Widdows J., Pope D.J. 2007. Effect of Cerastoderma edule density in near-bed hydrodynamics and stability of cohesive muddy sediments. J. Exp. Mar. Biol. Ecol. 346: 114-116.

Commito J.A., Thrush S.F., Pridmore R.D., Hewitt J.E., Cummings
V.J. 1995. Dispersal dynamics in a wind-driven benthic system. Limnol. Oceanogr. 40: 1513-1518.

Commito J.A., Celano E.A., Celico H.J., Como S., Johnson C.P. 2005. Mussels matter: Postlarval dispersal dynamics altered by a spatially complex ecosystem engineer. J. Exp. Mar. Biol. Ecol. 316: 133-147.

de Montaudouin X. 1997. Potential of bivalves' secondary settlement differs with species: a comparasion between cockle $(\mathrm{Ce}$ rastoderma edule) and clam (Ruditapes philippnarum) juvenile resuspension. Mar. Biol. 128: 639-648.

de Montaudouin X., Bachelet B. 1996. Experimental evidence of complex interactions between biotic and abiotic factors in dynamics of an intertidal population of the bivalve Cerastoderma edule. Ocean. Acta 19: 449-463.

de Montaudouin X., Bachelet B., Sauriau P.-G. 2003. Secondary settlement of cockles Cerastoderma edule as a function of current velocity and substratum: a flume study with benthic juveniles. Hydrobiology 203: 103-116.

García M.H. 2006. Lecture Notes on Sediment Transport. Ven Te Chow Hydrosystems Lab. University of Illionis at UrbanaChampaign, 192 pp.

Hunt H.L. 2004. Transport of juvenile clams: effects of species and sediment grain size. J. Exp. Mar. Biol. Ecol. 312: 271-284.

Hunt H.L., Maltais M.-J., Fugate D.C., Chant R.J. 2007. Spatial and temporal variability in juvenile bivalve dispersal: effects of sediment transport and flow regime. Mar. Ecol. Prog. Ser. 352: 145-159.

Jennings L.B., Hunt H.L. 2009. Distances of dispersal of juvenile bivalves (Mya arenaria (Linnaeus), Mercenaria mercenaria (Linnaeus), Gemma gemma (Totten)). J. Exp. Mar. Biol. Ecol. 376: 76-84.

Jiménez J. 2004. Turbulent flow over rough walls. Annu. Rev. Fluid Mech. 36: 173-196.

Jonsson P.R., van Duren L.A., Amielh M., Asmus R., Aspden R.J., Daunys D., Friedrichs M., Friend P.L., Olivier F., Pope N., Precht E., Sauriau P.G., Schaaff E. 2006. Making water flow: a comparison of the hydrodynamic characteristics of 12 different benthic biological flumes. Aquat. Ecol. 40: 409-438.

Julien P.Y. 2002. River Mechanics. Cambridge University Press, Cambridge, 434 pp.

Lundquist C.J., Pilditch C.A., Cummings V.J. 2004. Behaviour controls post-settlement dispersal by the juvenile bivalves Austrovenus stutchburyi and Macomona liliana. J. Exp. Mar. Biol. Ecol. 306: 51-74.

Molares J., Parada J.M., Sánchez-Mata A., Martínez G., Darriba C., Rodal M., Carreira P., Varela T., Crego A., Mariño J. 2007. Gestión del banco marisquero de "Lombos do Ulla" desde 2002 a 2007. In: XI Congreso Nacional de Acuicultura, Vigo.

Nezu I., Nakagawa H. 1993. Turbulence in Open-Channel Flows. A.A. Balkema, Rotterdam, 281 pp.

Nikora V., McEwan I., McLean S., Coleman S., Pokrajac D., Walters R. 2007. Double-averaging concept for rough-bed openchannel and overland flows: Theoretical background. J. Hyd. Eng. 133: 873-883.

Nowell A.R.M., Jumars P.A. 1984. Flow environments of aquatic benthos. Annu. Rev. Ecol. Syst. 15:303-328.

Parada J.M., Molares J., Sánchez-Mata A., Martínez G., Darriba C., Mariño J. 2006. Plan de actuación para la recuperación del banco "Lombos do Ulla": Campañas marisqueras desde 2002 a 2005 (in Spanish). Revista Galega dos Recursos Mariños 1: $1-37$.

Parada J.M., Molares J., Otero X. 2007. Episodios de mortalidad en el banco marisquero "Lombos do Ulla" (Ría de Arousa - NO de España) deducidos a partir de datos metereológicos de los últimos 45 años (in Spanish). In: XI Congreso Nacional de Acuicultura, Vigo.

Parker G. 1990. Surface-based bedload transport relation for gravel rivers. J. Hyd. Res. 28: 417-436.

Peña E., Anta J., Puertas J., Teijeiro T. 2008. Estimation of drag coefficient and settling velocity of the cockle Cerastoderma edule using Particle Image Velocimetry. J. Coast. Res. 24: 150-158.

Piedra-Cueva I., Mory M., Temperville A. 1997. A race-track recirculating flume for cohesive sediment research. J. Hyd. Res. 35: $377-396$.

Raffel M., Willert C., Wereley S., Kompenhans J. 2007. Particle Image Velocimetry. A practical guide. Springer, Berlin, 448 pp. Redjah I., Olivier F., Tremblay R., Myrand B., Pernet F., Neumeir 
U., Chevarie L. 2010. The importance of turbulent kinetic energy on transport of juvenile clams (Mya arenaria). Aquaculture 307: 20-28.

Richardson C.A., Ibarrola I., Ingham R.J. 1993. Emergence pattern and spatial distribution of the common cockle Cerastoderma edule. Mar. Ecol. Prog. Ser. 99: 71-81.

Roegner C., André C., Lindegarth M., Eckman J.E., Grant J. 1995. Transport of recently settled soft-chell clams (Mya arenaria L.) in laboratory flume flow. J. Exp. Mar. Biol. Ecol. 187: 13-26.

Sidgursson J.B., Titman C.W., Davies P.A. 1976. The dispersal of young post-larval bivalve molluses by byssus threads. Nature 262: 386-387.

St-Onge P., Miron G. 2007. Effects of current speed, shell length and type of sediment on the erosion and transport of juvenile softshell clams (Mya arenaria). J. Exp. Mar. Biol. Ecol. 349: 12-26.

St-Onge P., Miron G., Moreau G. 2007. Burrowing behaviour of the softshell clam (Mya arenaria) following erosion and transport. J. Exp. Mar. Biol. Ecol. 340: 103-111.
Underwood A.J. 1997. Experiments in Ecology. Their logical design and interpretaion using analysis of variance. Cambridge University Press, Cambridge, 504 pp.

Valanko S., Norkko A., Norkko J. 2010. Strategies of post-larval dispersal in non-tidal soft-sediment communities. J. Exp. Mar. Biol. Ecol. 384: 51-60.

van Duren L.A., Herman P.M.J., Sandee A.J.J., Heip C.H.R. 2006. Effects of mussel filtering activity on boundary layer structure. J. Sea Res. 55: 3-14.

Westerweel J. 1994. Efficient detection of spurious vectors in particle image velocimetry data. Exp. Fluids 16: 236-247.

Widdows J., Lucas J.S., Brinsley M.D., Salked P.N., Staff F.J. 2002. Investigation of the effects of current velocity on mussel feeding and mussel bed stability using an annular flume. Helgoländer Mar. Res. 56: 3-12.

Scient. ed.: J. Guillén.

Received September 28, 2012. Accepted April 9, 2013.

Published online May 27, 2013. 
APPENDIX 1. - Student-Newman-Keuls test for density $\times$ size $\times$ velocity interaction in the size class experiments. Treatment levels that are not significantly different at the 0.05 level are underlined.

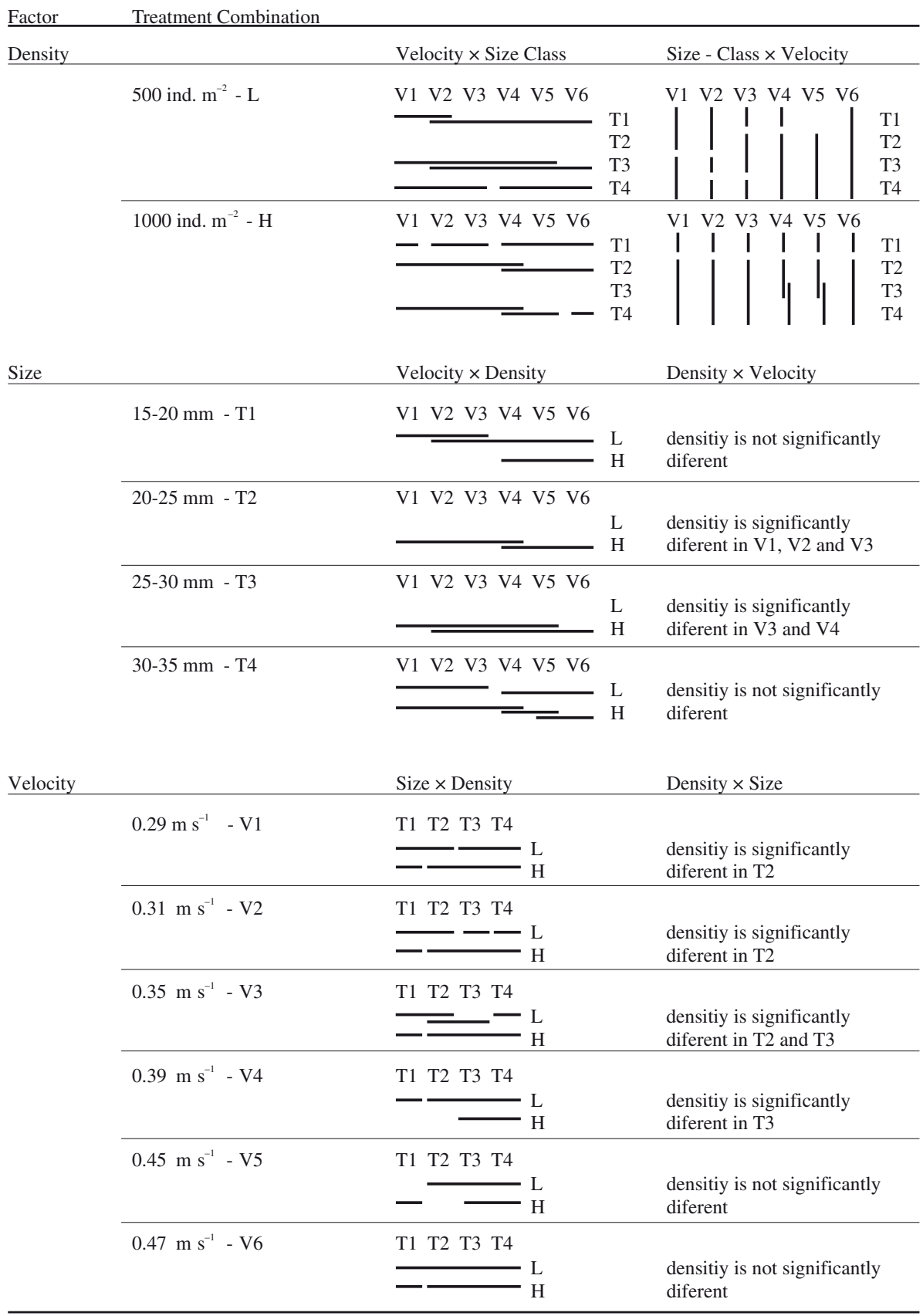

